\title{
Epidemiology of Giardiosis: Experience of the service of Parasitology Mycology the Military Hospital Avicenne: Review of 7 Years
}

\author{
Mouayche Ikhlas*, El Mezouari El Mostafa, Moutaj Redouane \\ Department of Parasitology and Mycology, Military Hospital Avicenne Marrakech, Faculty of Medicine and Pharmacy, Marrakech, Morocco \\ Email address: \\ I.Mouayche agmail.com (M. Ikhlas) \\ ${ }^{*}$ Corresponding author \\ To cite this article: \\ Mouayche Ikhlas, El Mezouari El Mostafa, Moutaj Redouane. Epidemiology of Giardiosis: Experience of the service of Parasitology \\ Mycology the Military Hospital Avicenne: Review of 7 Years. American Journal of Laboratory Medicine. Vol. 3, No. 4, 2018 , pp. 34-39. \\ doi: 10.11648/j.ajlm.20180304.11
}

Received: May 30, 2018; Accepted: August 13, 2018; Published: September 7, 2018

\begin{abstract}
The purpose of our work is to determine the epidemiological profile of giardiosis in the population of Marrakech and to propose the appropriate means to fight against this intestinal parasitosis. This is a descriptive analytical and retrospective study on the results of parasitological examinations of stool (EPS) performed within the Department of Parasitology Mycology at the Military Hospital Avicenna (HMA) of Marrakech over a period 7 years from January 2011 to December 2017.10615 parasitological examinations of stool (EPS) were performed in 6784 patients, 2651 of which were positive, ie a single parasite index of $25 \%$. Our study also included 669 EPS in children, 157 of which were positive. A parasite index of $23.4 \%$. Each patient received at least one PSE by including a direct examination associated with a concentration. Among the parasites encountered, Giardia intestinalis represents $6 \%$ of isolated parasites. This flagellate was observed in $32 \%$ of infested children. Two out of three children with giardiosis are aged between 11 and 15 years, this could have adverse consequences on their growth. Our results and those of the literature show that Giardiosis remains a more common parasitic disease in children than in adults. Giardiosis remains a frequent parasitosis in our country. It deserves to be better known, especially since it can induce serious manifestations. A policy of general and individual prophylaxis and an improvement of the social level in our country, will certainly lead to a considerable reduction of the prevalence of this parasitosis.
\end{abstract}

Keywords: Giardia, Child, Hygiene, Malabsorption

\section{Introduction}

Giardiasis is a fecal spread parasitosis caused by a flagellate Giardia intestinalis, a parasite of the human digestive tract and some animals most often found in the duodenum and jejunum. It occupies a special place in the digestive flagellosis as much by its frequency as by its pathogenic character. Giardiasis is a common parasitosis in children, often unknown or neglected, because it does not fall within the scope of diagnoses suggested by some clinical pictures. Indeed, when it evolves in a chronic mode, giardiosis is often responsible for a malabsorption syndrome that can be severe, particularly in children, with a break in the weight curve that can reach 10 to $20 \%$ usual or ideal body weight [1]. It is estimated that there are 280 million cases of
G. intestinalis infection per year worldwide, but mainly in Asia, Africa and Latin America. Symptomatic giardiasis involves about 200 million people and about 500000 new symptomatic cases per year are detected [2, 3]. The prevalence of giardiosis in developed countries ranges from $2 \%$ to $7 \%$ and ranges from $20 \%$ to $30 \%$ in developing countries. In the European Union in 2012, a total of 16,368 (5.43 per 100,000 population) of confirmed cases of giardiosis were documented. In Poland, according to the National Institute of Public Health about 2000 symptomatic cases of giardiosis are registered annually, most often in children and adolescents [4].

Morocco is no exception to this reality, since numerous ad hoc studies in certain regions of the kingdom have shown the endemic nature of intestinal parasites, in fact Giardia 
intestinalis can reach $10 \%$ of children in schools [5]. constitute a group at risk, because of the difficulty of ensuring effective hygiene at this age, and the cumbersome health impact of intestinal parasites (malnutrition, anemia, stunting...).

The aim of our study is to estimate the prevalence of intestinal giardiosis, and to approach the sociodemographic, hygienic and socioeconomic factors associated with parasite carriage in the study population, in order to assess the extent of the phenomenon and propose the appropriate means to fight against this public health problem.

\section{Materiels and Methods}

\subsection{Type, Location and Duration of the Study}

This is a descriptive analytical and retrospective study on the results of stool parasitological examinations (EPS) carried out in service of Parasitology Mycology at the Military Hospital Avicenne (HMA) of Marrakech over a period of 7 years ranging from from January 2011 to December 2017.

\subsection{Patients}

Adults and children (military and their families) hospitalized or consultants at the Avicenne Military Hospital (HMA) of Marrakech and civil patients referred hospitals Mohamed VI Hospital or the private sector.

The collection of information is based on the workbooks and registers of the mycology parasitology service of HMA.

Farm records including: the identity of the patients (name, first name, sex and age), the date of the analysis, the service and the results of the macroscopic and microscopic examinations of the EPS.

\subsection{Parasitological Study of Stool}

(a) Macroscopic study:

Each patient is given a clean, sterile jar to pick up his saddle from the morning of the day of the exam, and for patients referred for emergencies they are defecated for service. In all cases, the stool collected is examined as soon as possible after its emission, first macroscopically to note the appearance, consistency, color and the possible presence of blood, mucus and adult forms of parasites.

(b) Microscopic study:

Stool is carefully microscopically examined fresh $(0.9 \%$ saline solution) after staining with $2 \%$ Lugol or Merthiolate Iodine Formol (M. I. F) and after concentration by different techniques.

The reading of the preparations is done first at low magnification (x100) to detect helminth eggs and larvae and then at medium magnification $(\mathrm{x} 400)$ to search for vegetative and cystic forms of protozoa. (c) Concentration techniques:

To complete the parasitological analysis and to better highlight helminth eggs (often very few) and protozoan cysts, so-called concentration enrichment techniques have been adopted, the principle of which is to eliminate the digest residues and concentrate the parasitic elements in a small volume, taking advantage of the differences in densities and affinities of the faecal debris and the desired parasites. Two complementary methods are commonly prepared and used in the HMA parasitology department in Marrakech: the simplified RITCHIE method and that of WILLIS. Other ready-to-use kits with two associated methods are also used, such as COPRO DUO ${ }^{\circledR}$ and PARA-SELLES $®$.

\subsection{Statistical Analysis}

Statistical analysis was performed using SPSS software version 19.0. The descriptive analysis consisted of calculating the absolute and relative frequencies for the qualitative variables, and the positioning and dispersion parameters for the quantitative variables (mean, standard deviation).

The comparison of qualitative variables was based on the Chi2 and Fisher statistical test. The threshold of significance was retained for a $\mathrm{p}<0.05$.

\section{Results}

\subsection{Characteristics of the Studied Population}

We have included 4163 adults. They are divided into 3650 men is $87.67 \%$ and 513 women is $12.33 \%$. The sex ratio $(\mathrm{H} /$ F) was 7.11.

Our study also included 306 children, of which 198 girls $(64.86 \%)$ and 108 boys $(35.14 \%)$. The sex ratio (m/f) was 0.54 .

The military population was predominant with $66 \%$ of all examinations carried out.

Our study shows that $80.13 \%$ of people who have had parasitological examinations of stool are between 21 and 50 years old.

\subsection{Prevalence of Intestinal Parasites}

10615 parasitological examinations of stool (EPS) were performed in 6784 patients, of which 2651 examinations were positive, a simple parasite index of $25 \%$ (Table 1 and 2).

\subsection{Specific Parasite Index in Adults}

Amoebae come first and represent the most common parasites in the adult study population. Blastocystis hominis occupies the 2 nd position $22 \%$, followed by Giardia intestinalis in $6 \%$ of cases (Figure 1). 


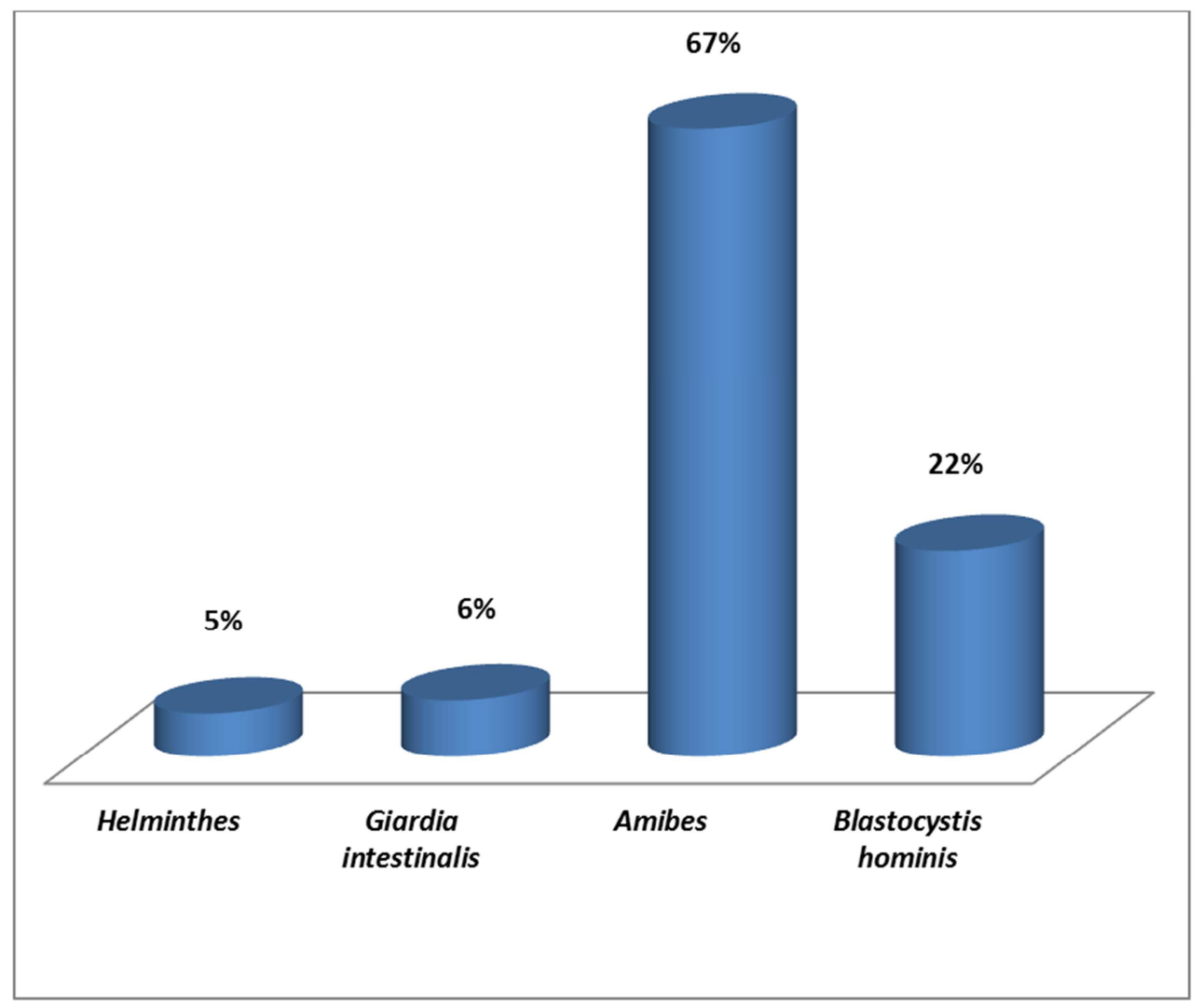

Figure 1. Prevalence of intestinal parasitism in adults.

\subsection{Specific Parasitic Index in Children}

The flagellates represented by Giardia intestinalis and helminths dominate the intestinal parasitism in children with respective frequencies of $21 \%$ and $36 \%$. As for amoebas, they represent $26 \%$ of positive exams and rank 3rd. Finally, Blastocystis hominis with a frequency of $6 \%$ of EPS (Figure 2) (Figure 3).

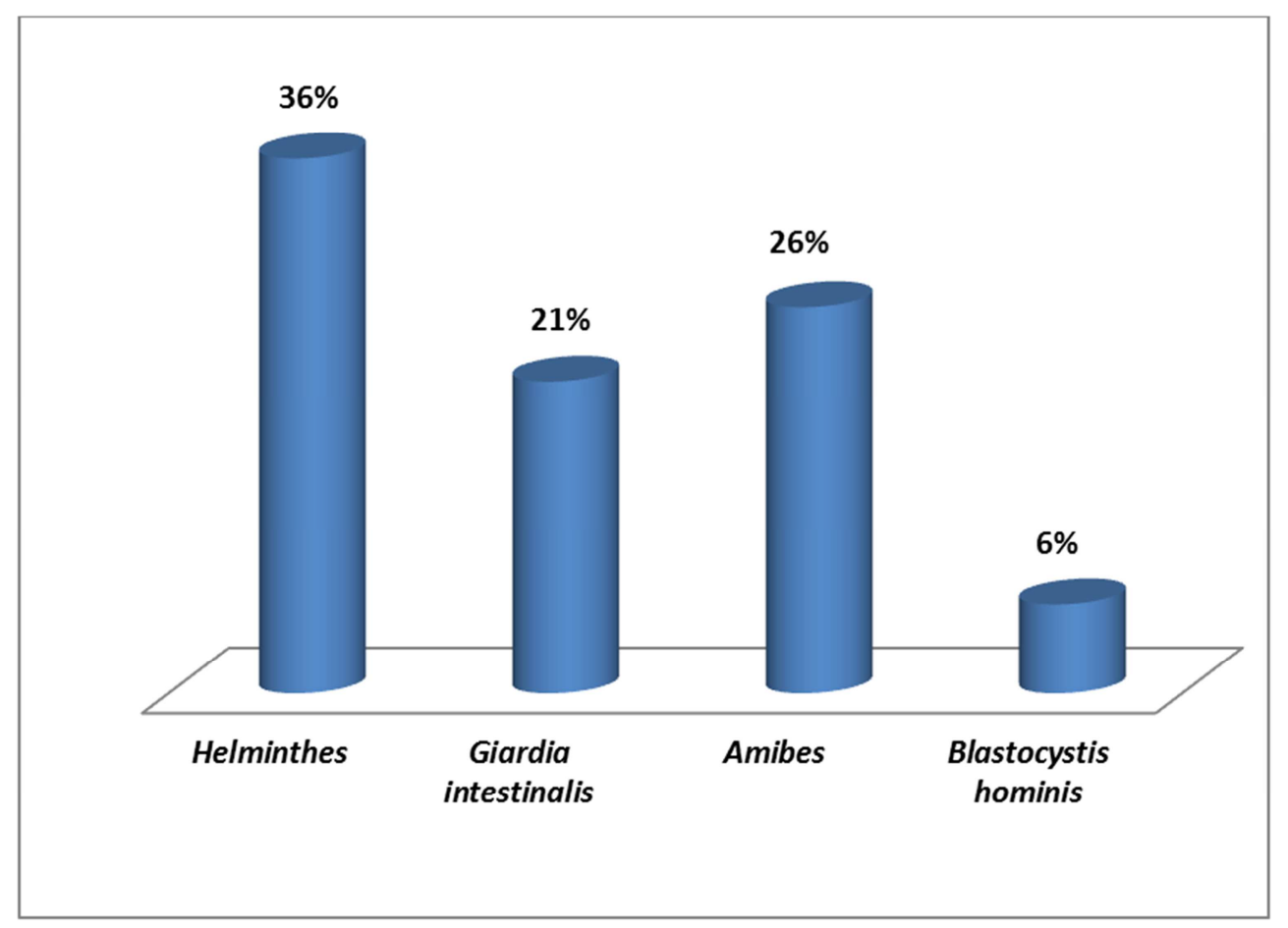

Figure 2. Prevalence of intestinal parasitism in children. 


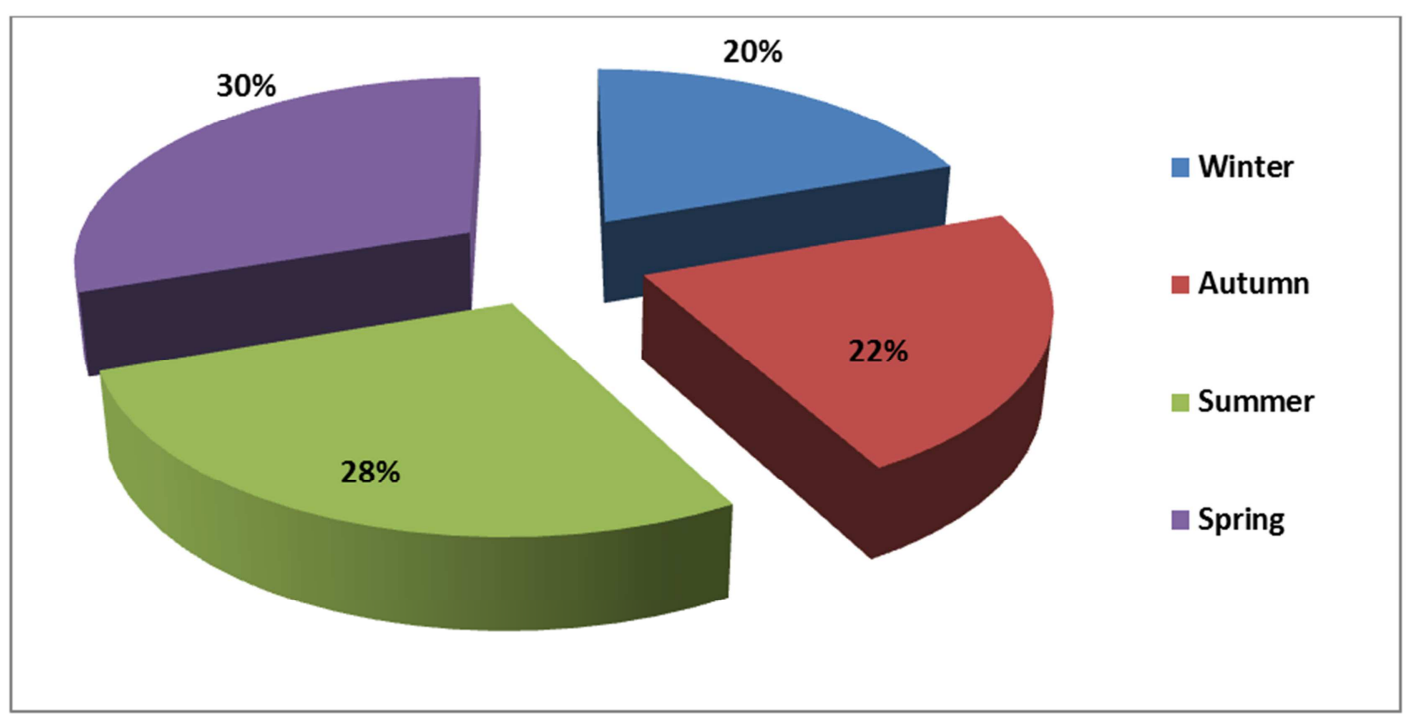

Figure 3. Frequency of Giardia intestinalis according to the seasons.

Table 1. Study of the population according to the years.

\begin{tabular}{llllllll}
\hline Years & $\mathbf{2 0 1 1}$ & $\mathbf{2 0 1 2}$ & $\mathbf{2 0 1 3}$ & $\mathbf{2 0 1 4}$ & $\mathbf{2 0 1 5}$ & $\mathbf{2 0 1 6}$ & $\mathbf{2 0 1 7}$ \\
\hline Number of EPS made in HMA & 1392 & 1493 & 1855 & 1769 & 1791 & 1258 & 1057 \\
\hline
\end{tabular}

Table 2. Simple parasite index in the study population.

\begin{tabular}{lll}
\hline & Number of E.P.S & Percentage \\
\hline Positive E.P.S & 2651 & $25 \%$ \\
Negative E.P.S & 7964 & $75 \%$ \\
Total & 10615 & $100 \%$ \\
\hline
\end{tabular}

\section{Discussion}

The total prevalence of intestinal parasitosis in our study population (25\%) was closer to that found in Tunisia and the Senegal River with a prevalence of $26.6 \%$ and $26.5 \%$ respectively $[1,2]$. This prevalence is higher than reported in Algeria (19.96\%) and Kenitra (14.15\%) [3, 4].

Our situation is intermediate between Europe, where the prevalence of digestive parasitism is low (9.2\% in Italy) and the tropical zone where it is much higher and often reaches or exceeds $50 \%$ [5]. This is particularly the case in sub-Saharan Africa: $36 \%$ to $40 \%$ and in Asia: $64.5 \%[6,7,8]$.

The analysis of the distribution according to the seasons revealed that the global parasitism notes a spring predominance and a slight spring-spring recredescence joining the study made in Tunisia [1]. In addition there is a manifestation during all the seasons of the year according to a study made in Kenitra [4]. These variations depend on the temperature and the humidity, which favor the maturation of the parasites as well as their terrestrial dissemination and consequently of the infectiousness of the infesting forms [9]. Certain eating habits, especially the consumption of raw water and poorly cleaned food (fruits, fresh vegetables, salads...) during the summer could strongly justify this recrudescence.

We note that sex in our work does not significantly influence the prevalence of intestinal parasitosis. This result is consistent with that of the study conducted in southern
Togo and Pikine in Senegal $[10,11]$. Similarly, for the distribution of parasite species according to the sex of the patients, no significant association has been established. In contrast, the Kenitra study asserts the presence of significant association: Entamoeba histolytica, Entamoeba coli are more common in females, while Giardia intestinalis and Ascaris Lumbricoides are more common in males [4].

In our study, the absence of a significant association between parasitism and the sex of the patients would be explained by the equality of exposure. Indeed, our patients are subject to the same environmental health conditions and suffer the same risks of infestation regardless of their gender.

We note that the prevalence of gut Giardiosis in the adult subject was of the order of $6 \%$ of cases. This rate is low compared to the prevalence recorded in adults in Kenitra by ELGUAMRI and that recorded in Tunis in 2006 [4, 12].

Intestinal parasitism in children included in our study series is uncommon compared with African studies, including those reported by Ayadi in Tunisia (25.09\%), Benouis in Algeria (28.84\%), O. FAYE to the Senegal River (30\%), ISSAKA in Burkina Faso (30.7\%) Ould Ahmed in Mauritania (33.4\%), Adou-Bryn in Côte d'Ivoire (38.9\%) and Makhtar in Senegal (57\%), (10\%) [13, 3, 2, 16, 17, 18, 19]. This difference, quite important, could be explained by the urban origin of the majority of our child population, and their socio-economic level quite good (Table 3 ). 
Table 3. Prevalence of parasitic infections in children in the countries of the sub-region.

\begin{tabular}{|c|c|c|c|c|c|c|c|}
\hline & $\begin{array}{l}\text { Issaka } \\
\text { Burkinafaso }\end{array}$ & $\begin{array}{l}\text { Adou-Bryn Cote } \\
\text { d'ivoire } 2001\end{array}$ & $\begin{array}{l}\text { Makhtar } \\
\text { Sénégal } 2001\end{array}$ & $\begin{array}{l}\text { O.Faye Sénégal } \\
1989\end{array}$ & $\begin{array}{l}\text { Ouldahmed } \\
\text { Mauritae } 2011\end{array}$ & $\begin{array}{l}\text { Benous Algérie } \\
2013\end{array}$ & $\begin{array}{l}\text { Our series } \\
\text { Marrakech } 2017\end{array}$ \\
\hline Number of children & $\begin{array}{l}700 \\
\text { Schoolchildren }\end{array}$ & 357 children & $\begin{array}{l}170 \\
\text { Schoolchildren }\end{array}$ & $\begin{array}{l}4581 \\
\text { Schoolchildren }\end{array}$ & 1308 children & not indicated & 306 children \\
\hline Middle of The study & Urban & Urban & Rural & Rural & Rural & not indicated & Urban \\
\hline Prevalence & $30.7 \%$ & $38.9 \%$ & $57.1 \%$ & $30 \%$ & $33.4 \%$ & $28.8 \%$ & $21 \%$ \\
\hline
\end{tabular}

The prevention of giardiosis requires proper handling and treatment of the water used for the communities and good personal hygiene on an individual basis. Although chlorination alone is sufficient to kill G. Lamblia Cysts, significant variations, such as water temperature, clarity, $\mathrm{pH}$ and contact time,

alter the effectiveness of chlorine, and levels of higher chlorine levels (4 to $6 \mathrm{mg} / \mathrm{L}$ ) may be required. Thus, in addition to this technique, public water reserves must also be subjected to sedimentation and filtration in addition to the procedures in force particularly in rural areas [20].

Better prevention must pass through the following measures [21, 22]:

1) limit the spread of Giardia cysts by good prevention and fight against the faecal danger that it is on the individual or collective plan.

2) detect and treat healthy carriers who disseminate cysts and provide latrines to the population for better management of human waste.

3) facilitate access to drinking water and educate the population about hand hygiene, food and water.

4) The prohibition of spreading human faeces for agriculture is of paramount importance.

5) The strict respect of hygiene rules from childhood: washing hands after each bowel movement and before each meal, ingestion of filtered or boiled water, careful cleaning of raw vegetables and fruits with clean water

\section{Conclusion}

Giardiasis remains a frequent parasitosis in our country. It deserves to be better known, especially since it can induce serious manifestations, in particular by the repercussions on intestinal absorption. This parasitosis continues to be a common occurrence among young children despite improvements in the level of hygiene. It can be incriminated in the weight stunting retardation in the child, hence the interest of systematic research of this parasite before any stunting. The socio-economic level seems to be a very important parameter, since giardiosis is more frequent in patients belonging to more or less disadvantaged backgrounds. Parasitological stool examination is the test of choice for the diagnosis of giardiasis provided that it is performed under good conditions and repeated three times at several days intervals. The Giardia Antigen copro can be a diagnostic supplement. Nitro-5-imidazoles, is the family most used to treat this parasitosis. A policy of general and individual prophylaxis and an improvement of the social level in our country, will certainly lead to a considerable reduction of the prevalence of this parasitosis.

The present work shows a relatively low prevalence of Giardiosis among the military majority of the study population, some sort of city dwellers. Such a statement can in no way be a reflection of the reality of the state of health of all Moroccans but it remains nonetheless that it is a state of patients living in urban areas. Other similar studies should be conducted especially in rural areas and particularly in children to better serve the establishment of the Moroccan spectrum for this flagellosis with all its epidemiological characteristics.

At the end of this work, we propose some attitudes to take:

1) Regular control of cooks and people handling raw food.

2) Food and therapeutic preparation of the patient first and foremost E.P.S.

3) send freshly issued stools to the laboratory as soon as possible.

4) The repetition of EPS 3 times spaced a few days because parasitologically silent periods.

5) Ask for clinical information, which determines the choice of methods of analysis.

6) Choose 2 parasite concentration techniques, a standard and a parasite-oriented 2 nd one to look for.

7) Antiparasitics should only be prescribed after biological confirmation.

8) Establishment of a parasite screening program in schools and in communities (nurseries, retirement homes, psychiatry...).

9) Ensure the sanitary quality of food ready for consumption.

10)Respect the general rules of individual and collective hygiene.

11)Treat cases of parasitism to break the parasitic chain of transmission.

\section{References}

[1] Cheikhrouhou F, Trabelsi H, Sellami H, Makni F, Ayadi A. Parasitoses Intestinales Dans La Region De Sfax (Sud Tunisien): Étude Retrospective. Rev Tun Infectiol, Avril 2009; 3(2)14-18.

[2] Faye O, N'Dir O, Gaye O, Dieng Y, Dieng T et al. Les parasitoses intestinales dans le bassin du fleuve Sénégal: Résultats d'enquêtes effectuées en milieu rural. Méd. Afrique Noire. 1998; 45(8/9): 491-495. 
[3] Benouis A, Bekkouche Z, Benmansour Z. Etude épidémiologique des parasitoses intestinales humaines au niveau du C. H. U. d'Oran. International Journal of Innovation and Applied Studies. 2013; 2: 613-20.

[4] El Guamri Y, Belghyti D, Barkia A, Tiabi M, Aujjar N, Achicha A. Bilan de dix ans sur les parasitoses intestinales au Centre Hospitalier de Kenitra (Maroc) 1996-2005. Science Lib. 2011; 3:1-11.

[5] Cutrupi V, Bernieri F, Crotti D et al. Les parasitoses intestinales observées dans quatre régions d'Italie en 1994 et 1995. Bull Soc Fr Parasitol. 1996; 14(1): 85-8.

[6] Buchy P. Les parasitoses digestives dans la région de Mahajanga, Côte Ouest de Madagascar. Bull Soc Pathol Exot. 2003; 96(1): 41-5.

[7] Julvez J, Badei M. Lamotte M. Les parasitoses intestinales dans l'environnement urbain au Sahel, Etude dans un quartier de Niamey, Niger. Bull Soc Pathol Exot. 1998; 91(5-5bis): 424-27.

[8] Kim BJ, Ock MS, Chung DI, Yong TS, Lee KJ. The intestinal parasite infection status of inhabitants in the Roxas city, The Phill. P. Pines. Korean J Parasitol. 2003; 41(2): 113-5.

[9] Ngindu A, Kamar K, Choge A, Maritim A et al. Survey of faecal parasites in patients from western Kenya. J Egyp Soc Parasitol. 2002; 32(1):1-7

[10] Aplogan A, Schneider D, Dyck JL, Berger L. Parasitose digestives chez le jeune enfant en milieu extra Hospitalier Tropical (Sud Togo). Ann. Pédiatrie (Paris). 1990; 37(10):677681.

[11] Salem G, Van De Velden L, Laloé F, Maire B, Ponton A, Traissac P, Prost A. Parasitoses intestinales et environnement dans les villes Sahélo-Soudaniennes: l'exemple de Pikine (Sénégal). Rev. Epidém. Santé Publ. 1994; 42(4), 322-333.

[12] Belhamri N. MOUTAJ. Profil épidémiologique des parasitoses intestinales au service de Parasitologie Mycologie à l'Hôpital Militaire Avicenne de Marrakech. Thèse de doctorat en médecine, faculté de médecine et pharmacie Marrakech; 2015.
[13] EL Kettani S., Azzouzi E. M., Maata A., Prévalence de Giardia intestinalis chez une population rurale utilisant les eaux usées à des fins agricoles à Settat, Maroc, Méd. Mal. Infect. 36 (2006) 322-328.

[14] Benouis A, Bekkouche Z, Benmansour Z. Etude épidémiologique des parasitoses intestinales humaines au niveau du C. H. U. d'Oran. International Journal of Innovation and Applied Studies. 2013; 2: 613-20.

[15] Faye O, N'Dir O, Gaye O, Dieng Y, Dieng T et al. Les parasitoses intestinales dans le bassin du fleuve Sénégal: Résultats d'enquêtes effectuées en milieu rural. Méd. Afrique Noire. 1998; 45(8/9): 491-495.

[16] Ayadi A., Les maladies parasitaires à transmission hydrique, Tech. Biol. 5 (1992) 140-146.

[17] Belosevic M., Faubert G. M., Maelean J. D., Disaccharidase activity in the small intestine of gerbils (meriones in guinculatus) during primary and challenge infections with Giardia lamblia, GWF 30 (1989) 1213-1219.

[18] Buret A. G., Mechanisms of epithelial dysfunction in giardiasis, Gut. 56(3) (2007) 316-317.

[19] Das K., Sachdeva S., Misra A., Ghoshal U. C., Malabsorption syndrome due to various causes is associated with antroduodenal hypomotility, Indian J. Gastroenterol. 25(2) (2006) 58-61.

[20] Allain, T; Chaouch, S; Thomas, M; Travers, A; Vallee, I; et al. ROLE DES PROBIOTIQUES DANS LE TRAITEMENT DE LA GIARDIOSE. Archives de l'Institut Pasteur de Tunis; Tunis Vol. 92, $\mathrm{N}^{\circ}$ 1/2, (2015): 78.

[21] Matthew Washam and Robert W. Frenck, Jr. Giardia intestinalis (Giardiasis) 2018.

[22] Feng Y, Xiao L. Zoonotic potential and molecular epidemiology of Giardia species and giardiasis. Clin Microbiol Rev 2011; 24: 110-140. 